\title{
Death after percutaneous dilatational tracheostomy: a systematic review and analysis of risk factors
}

Marcel Simon ${ }^{1 \dagger}$, Maria Metschke ${ }^{1 \dagger}$, Stephan A Braune ${ }^{1}$, Klaus Püschel $^{2}$ and Stefan Kluge ${ }^{1 *}$

\begin{abstract}
Introduction: Since the introduction and widespread acceptance of percutaneous techniques in the intensive care unit (ICU) setting, the number of critically ill patients undergoing tracheostomy has steadily increased. However, this procedure can be associated with major complications, including death. The purpose of this study is to estimate the incidence and analyze the causes of lethal complications due to percutaneous dilatational tracheostomy (PDT).

Methods: We analyzed cases of lethal outcome due to complications from PDT including cases published between 1985 and April 2013. A systematic literature search was performed and unpublished cases from our own departmental records were retrospectively analyzed.

Results: A total of 71 cases of lethal outcome following PDT were identified including 68 published cases and 3 of our own patients. The incidence of lethal complications was calculated to be $0.17 \%$. Of the fatal complications, $31.0 \%$ occurred during the procedure and $49.3 \%$ within seven days of the procedure. The main causes of death were: hemorrhage (38.0\%), airway complications (29.6\%), tracheal perforation (15.5\%), and pneumothorax (5.6\%). We found specific risk factors for complications in $73.2 \%$ of patients, $25.4 \%$ of patients had more than one risk factor. Bronchoscopic guidance was used in only $46.5 \%$ of cases.

Conclusions: According to this analysis, PDT-related death occurs in 1 out of 600 patients receiving a PDT. Careful patient selection, bronchoscopic guidance, and securing the tracheal cannula with sutures are likely to reduce complication rates.
\end{abstract}

\section{Introduction}

Since the introduction and widespread acceptance of percutaneous techniques in the intensive care unit (ICU) setting, the number of critically ill patients undergoing tracheostomy has increased in recent years [1,2]. Given a predicted increase in the numbers of mechanically ventilated patients, a further increase in the number of tracheostomy procedures in the ICU is to be expected [1-4].

The ideal timing of tracheostomy is still a subject of debate as there is no clear evidence that early tracheostomy improves relevant endpoints, such as duration of mechanical ventilation, length of ICU stay, and mortality

\footnotetext{
* Correspondence: s.kluge@uke.de

${ }^{\dagger}$ Equal contributors

${ }^{1}$ Department of Intensive Care Medicine, University Medical Center Hamburg-Eppendorf, Martinistr 52, 20246 Hamburg, Germany Full list of author information is available at the end of the article
}

[5]. Nevertheless, tracheostomy is being undertaken significantly earlier during ICU stay, as the intervention appears to be beneficial in terms of patient comfort, mobility, and reducing the requirement for sedation $[1,6]$. Percutaneous dilatational tracheostomy (PDT) has gained wide acceptance and has become the procedure of choice for tracheostomy in critically ill patients worldwide [7]. However this procedure, just like surgical tracheostomy, is associated with major complications, including death. It is estimated that each year approximately 500 patients in the United States die or are permanently disabled because of a tracheostomy [8].

Three fatalities due to PDT in our department in recent years prompted us to perform this study. We aimed to analyze cases from the literature and from our own database to determine the incidence of lethal complications due to percutaneous tracheostomy, to reveal the causes of death, to identify risk factors and possible mechanisms for

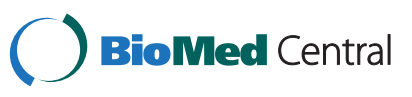


lethal complications, and finally to develop recommendations to further minimize the risks of complication.

\section{Materials and methods}

The study was conducted and reported according to PRISMA guidelines [9].

\section{Search strategy}

A systematic search for articles was performed in PubMed, Embase and the Cochrane Library without restrictions for language searching for case reports, case series, observational studies and randomized trials describing or including fatalities associated with PDT. We focused on studies published from 1985 onward as the percutaneous approach gained popularity after its description by Ciaglia et al. [10] in that specific year.

An extensive and sensitive search strategy was chosen using the keywords 'percutaneous tracheostomy' and 'percutaneous tracheotomy' to ensure comprehensive retrieval of articles. The search was last updated on 30 April 2013.

\section{Study selection}

Studies were selected independently by two authors (MS and SK). Disagreements between the two authors were resolved by discussion. The titles and abstracts of all publications retrieved by the search strategy were screened for eligibility. Studies on PDT were selected for further evaluation. Full-text review of these studies was performed. Studies were included if one or more PDT-related deaths were described. In addition, the reference sections of all studies on PDT were handsearched for additional relevant publications.

\section{Data extraction, assessment, completion and synthesis}

Data was independently extracted with standardized forms and interpreted by three authors (MS, SB, SK). The results of data extraction were then compared and disagreement resolved by discussion. Included publications were reviewed manually for relevant data. Information concerning patient characteristics (age, gender, main diagnosis, and duration of mechanical ventilation before tracheostomy), tracheostomy procedure (technique, bronchoscopic guidance, pre-interventional ultrasound, performing physician or team, procedure-related difficulties, special circumstances, and risk factors for complications), cause and time of death as well as departmental characteristics (type of ICU, year of introduction of PDT in the department, number of PDTs performed annually and the number of fatalities related to PDT since its introduction in the department) was extracted. If the published data set was incomplete, we contacted the corresponding author via email or post. If the corresponding author did not respond within four weeks, we sent a reminder.
Retrieval of PDT-related fatalities from our own department To identify tracheostomy-related fatalities in our own department, all patients who had undergone PDT between 1 January 2005 and 31 December 2012 were identified from the departmental electronic patient database. Cases retrieved from this search were further evaluated for procedure-related deaths by manual analysis of their medical records.

Since 1st January 2005, the Ciaglia Blue Rhino ${ }^{\text {tax }}$ technique assisted by bronchoscopic guidance has been the standard technique for PDT in our department. The PDTs were performed at the bedside in one of the 10 departmental ICUs according to a standardized operating procedure [11]. After completion, a protocol documenting key aspects of the procedure was generated and saved in the electronic medical record.

The ethics committee of the Hamburg Chamber of Physicians and the institutional data protection official approved the collection, analysis, and publication of the retrospectively obtained and anonymized data for this noninterventional study.

\section{Data analysis}

Results are presented as medians and ranges or as absolute numbers with percentages. The software used for descriptive analyses was Microsoft Excel 2011 (Microsoft Corp., Redmond, WA, USA).

\section{Results}

\section{Study and case selection}

The search strategy yielded a total of 1,963 articles. From these publications 45 studies describing 65 PDTrelated fatalities were included in the study. Three more cases could be added from personal communication with the corresponding authors. Three additional cases were included from our own departmental records. Overall, 71 cases of PDT-related death were included and analyzed in this study. The process of case selection is summarized in Figure 1.

By contacting the corresponding authors, case specific data could be added in 20 cases and departmental data concerning the total numbers of PDT procedures and PDT-related fatalities could be obtained from 17 departments.

\section{Study characteristics}

We found sixteen case reports or case series, seven retrospective studies, twenty prospective observational studies and two randomized trials. Study characteristics are summarized in Table 1.

\section{Summary and analysis of all cases}

The median age was 66 years (range 4 to 95). For further details concerning patient characteristics see Table 2 . 


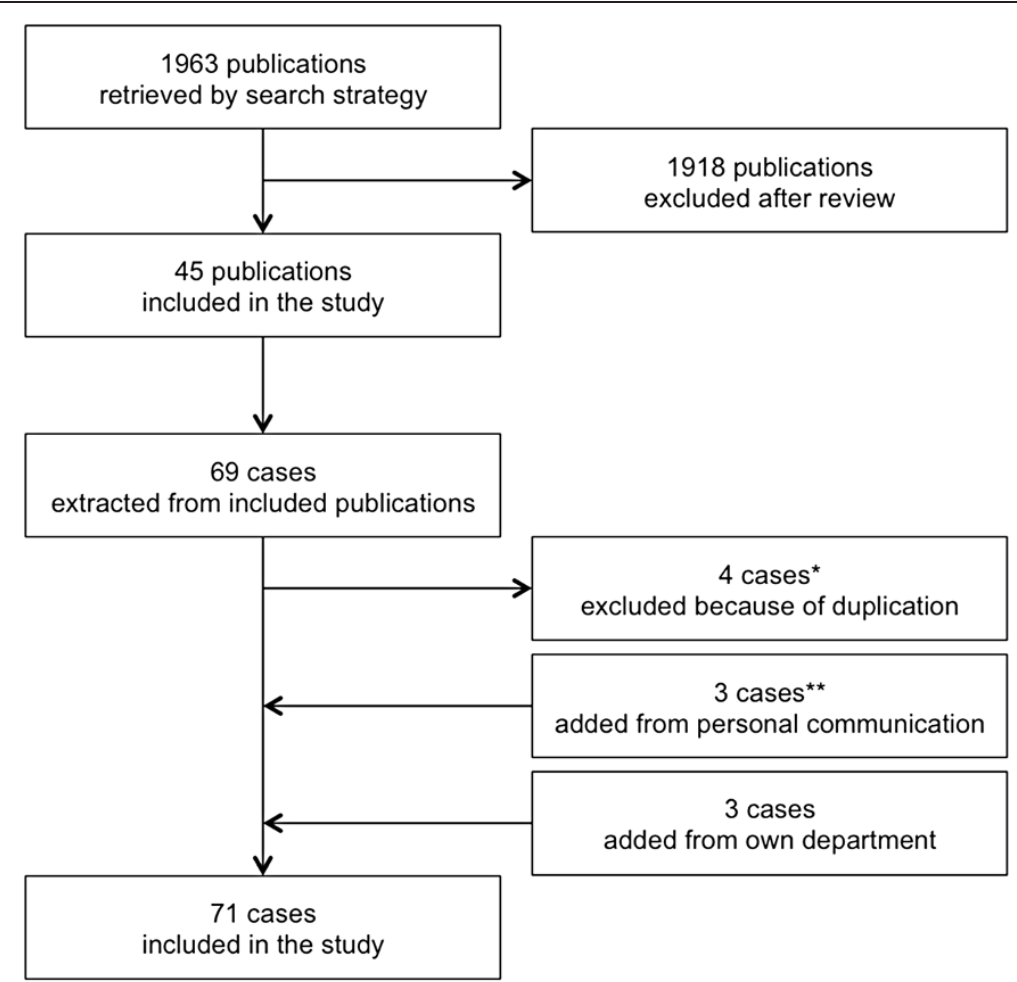

Figure 1 Process of case selection. ${ }^{*}[12-14] .{ }^{*}[15,16]$.

Most tracheostomies were performed using the Ciaglia (45.1\%) and the Ciaglia Blue Rhino ${ }^{\mathrm{m}}$ (26.8\%) technique. Bronchoscopic guidance was used in $46.5 \%$ of cases, but no cases involved pre- or peri-interventional ultrasound.

The major causes of death were tracheostomy-related hemorrhage in 27 patients (38.0\%) and airway complications in 21 patients (29.6\%). In $31.0 \%$ of cases, fatal complications occurred during the procedure and in $49.3 \%$ of cases within seven days of the procedure. $73.2 \%$ of patients had specific risk factors and $25.4 \%$ of patients had more than one risk factor. For further details about the causes of death and time of complications see Table 3.

\section{Hemorrhage}

We found 27 deaths $(38.0 \%)$ due to hemorrhage $[18,19$, $22-26,28-31,35,37,39,43,46,49,54,57-59]$. The source of bleeding was arterial in 16 cases (59.3\%). Most often arterial bleeding originated from tracheovascular fistula formation involving the innominate artery (11 cases). The majority of bleeding incidents $(75.0 \%)$ occurred between one day and one month after the tracheostomy procedure, with a median of five days. The following known risk factors were retrospectively attributed as potentially relevant in these fatalities secondary to hemorrhagic complications: not using bronchoscopic guidance (eight cases), low tracheostomy site (five cases), coagulopathy (five cases), previous surgery to the neck (four cases), previous radiotherapy (one case), obesity (one case), anatomical abnormality (one case), paratracheal misplacement of the tracheal cannula (one case), malpositioned cannula tip (one case), and high cuff pressure (one case). Twenty-one patients $(77.8 \%)$ had at least one of the described risk factors.

\section{Airway complications}

Twenty-one deaths (29.6\%) due to airway complications were reported [32,34,38-40,42,44,48,50-53,56,60,61]. Main causes of death in this group were dislocation of the tracheal cannula (52.4\%), lost airway during the procedure (19.0\%) and paratracheal misplacement of the tracheal cannula (14.3\%). Performing the procedure without bronchoscopic guidance (six cases), by a team relatively inexperienced with the procedure (five cases), in obese patients (eight cases), in patients with a difficult airway (two cases), not securing the tracheal cannula with sutures (three cases), early cannula replacement (one case), and post-procedural care by an inexperienced team (one case) were determined as risk factors for these fatalities attributed to airway complications. Nineteen patients (90.5\%) had at least one of the described risk factors.

\section{Tracheal perforation}

Including our own cases, a total of 11 deaths (15.5\%) were due to tracheal perforation $[17,20,47,49,53,57,59]$. 
Table 1 Characteristics of studies included

Study

\begin{tabular}{|c|c|c|c|c|c|c|c|c|c|c|}
\hline & \multirow{3}{*}{ Year } & \multirow{3}{*}{$\begin{array}{c}\text { Design } \\
C R\end{array}$} & & \multirow{3}{*}{$\begin{array}{c}\text { Number of } \\
\text { PDTs }\end{array}$} & \multirow{3}{*}{$\begin{array}{c}\begin{array}{c}\text { Number of } \\
\text { deaths }\end{array} \\
2\end{array}$} & \multirow[b]{2}{*}{$\begin{array}{l}\text { Mortality } \\
\text { rate }\end{array}$} & \\
\hline Author & & & & & & & & $\begin{array}{l}\text { Number of } \\
\text { PDTs }\end{array}$ & $\begin{array}{c}\text { Number of } \\
\text { deaths }\end{array}$ & $\begin{array}{l}\text { Mortality } \\
\text { rate }\end{array}$ \\
\hline Byhahn & [16] & & & & & & & & & \\
\hline Cobean & [15] & & $C R$ & & & 1 & & & & \\
\hline Hutchinson & [17] & 1991 & $C R$ & & & 1 & & & & \\
\hline Cokis & [18] & 2000 & $C R$ & & & 1 & & & & \\
\hline Hürter & [19] & 2000 & $C R$ & Surgical & & 1 & & 252 & 2 & 0.79 \\
\hline Drage & [20] & 2002 & $C R$ & & & 1 & & & & \\
\hline Maeda & [21] & 2002 & $C R$ & Mixed & & 1 & & & & \\
\hline Soubirou & [22] & 2002 & $C R$ & Surgical & & 1 & & & & \\
\hline Ryan & [23] & 2003 & $C R$ & & & 1 & & & & \\
\hline Shlugman & [24] & 2003 & $C R$ & Neurological & & 1 & & 700 & 1 & 0.14 \\
\hline McCormick & [25] & 2005 & $C R$ & Mixed & & 3 & & 2,100 & 4 & 0.19 \\
\hline Grant & [26] & 2006 & $C R$ & Mixed & & 3 & & & & \\
\hline Rosolski & [27] & 2006 & $C R$ & Mixed & & 1 & & 420 & 1 & 0.24 \\
\hline Ayoub & [28] & 2007 & $C R$ & & & 1 & & & & \\
\hline Zehlicke & [29] & 2007 & $C R$ & & & 1 & & & & \\
\hline Wang & [30] & 2009 & $C R$ & & & 1 & & & & \\
\hline Hoiting & [31] & 2010 & $C R$ & & & 2 & & & & \\
\hline Gilbey & [32] & 2012 & $C R$ & Mixed & & 1 & & 420 & 1 & 0.24 \\
\hline Ivatury & [33] & 1992 & RS & & 61 & 1 & 1.64 & & & \\
\hline Cobean & [34] & 1996 & RS & Mixed & 65 & 1 & 1.54 & 1,080 & 2 & 0.19 \\
\hline van Heurn & [35] & 1996 & RS & Mixed & 150 & 1 & 0.67 & 880 & 1 & 0.11 \\
\hline Thompson & [36] & 2001 & RS & Medical & 300 & 1 & 0.33 & & & \\
\hline Pandit & [37] & 2006 & RS & Mixed & 501 & 1 & 0.20 & 1,265 & 2 & 0.16 \\
\hline Klein & [38] & 2007 & RS & Mixed & 207 & 1 & 0.48 & & & \\
\hline Dennis & [39] & 2013 & $\mathrm{RS}$ & & 3162 & 5 & 0.16 & 3,162 & 5 & 0.16 \\
\hline Toye & [40] & 1986 & POS & & 94 & 1 & 1.06 & & & \\
\hline Marelli & [41] & 1990 & POS & & 61 & 1 & 1.64 & & & \\
\hline Wang & [42] & 1992 & POS & Surgical & 7 & 1 & 14.29 & & & \\
\hline Friedman & [43] & 1993 & POS & & 100 & 1 & 1.00 & & & \\
\hline Cole & [44] & 1994 & POS & & 55 & 1 & 1.82 & & & \\
\hline Barba & [45] & 1995 & POS & Surgical & 27 & 1 & 3.70 & & & \\
\hline Muhl & [46] & 1995 & POS & Surgical & 14 & 1 & 7.14 & 720 & 1 & 0.14 \\
\hline Joosten & [47] & 1996 & POS & Surgical & 53 & 1 & 1.89 & 420 & 1 & 0.24 \\
\hline$\overline{M a r x}$ & [48] & 1996 & POS & & 254 & 1 & 0.39 & & & \\
\hline Berrouschot & [49] & 1997 & POS & Neurological & 76 & 2 & 2.63 & 900 & 2 & 0.22 \\
\hline$\overline{\text { Walz }}$ & [50] & 1998 & POS & & 337 & 2 & 0.59 & & & \\
\hline$\overline{\text { Suh }}$ & [51] & 1999 & POS & & 95 & 2 & 2.11 & 1,040 & 2 & 0.19 \\
\hline Escarment & [52] & 2000 & POS & & 162 & 2 & 1.23 & & & \\
\hline Kearney & [53] & 2000 & POS & Mixed & 827 & 5 & 0.60 & 5,400 & 9 & 0.17 \\
\hline Lim & [54] & 2000 & POS & & 261 & 2 & 0.77 & & & \\
\hline Norwood & [55] & 2000 & POS & & 422 & 1 & 0.24 & & & \\
\hline$\overline{\operatorname{Tan}}$ & [56] & 2004 & POS & & 352 & 1 & 0.28 & & & \\
\hline Byhahn & [57] & 2005 & POS & Surgical & 474 & 2 & 0.42 & 2,775 & 4 & 0.14 \\
\hline$\overline{C h i u}$ & [58] & 2005 & POS & Medical & 107 & 1 & 0.93 & 900 & 1 & 0.11 \\
\hline
\end{tabular}

Departmental data obtained by personal communication with the corresponding author 
Table 1 Characteristics of studies included (Continued)

\begin{tabular}{llllllllll}
\hline Páez & {$[59]$} & 2005 & POS & & 38 & 2 & 5.26 & & \\
\hline Porter & {$[60]$} & 1999 & RT & Surgical & 12 & 1 & 8.33 & & \\
\hline Massick & {$[61]$} & 2001 & RT & Medical & 50 & 1 & 2.00 & & 3 \\
\hline Own cases & & & Mixed & & 3 & & 1,873 & $\mathbf{2 4 , 3 0 7}$ & $\mathbf{4 2}$ \\
\hline Summary & & & & $\mathbf{8 3 2 4}$ & $\mathbf{7 1}$ & $\mathbf{2 . 1 8 ^ { * }}$ & $\mathbf{0 . 1 7}$ \\
\hline
\end{tabular}

${ }^{*}$ Calculated mean mortality rate including data from retrospective studies, prospective observational studies and randomized trials. $C R$, case report, $R S$, retrospective study, $P O S$, prospective observational study, $R T$, randomized trial.

Performing the procedure without using bronchoscopy (five cases), by an inexperienced team (four cases), in an obese patient (one case), in a child (one case), noticing a kinking of the guidewire postprocedurally (two cases), and anatomic abnormalities of the spine (one case) were determined as risk factors for this kind of complication. Nine patients $(81.8 \%)$ had at least one of the described risk factors.

\section{Pneumothorax}

Four deaths $(5.6 \%)$ resulting from a pneumothorax were reported $[15,27,36,55]$. Two deaths were due to tension pneumothoraces and two were due to bilateral pneumothorax. Primary symptoms were subcutaneous emphysema

Table 2 Patient characteristics

\begin{tabular}{|c|c|c|}
\hline Characteristic & Values & \\
\hline Number of patients & 71 & \\
\hline Median age (years) & 66 & (range 4-95 \\
\hline \multicolumn{3}{|l|}{ Gender } \\
\hline female & 33 & $(46.5 \%)$ \\
\hline male & 16 & $(22.5 \%)$ \\
\hline not specified & 22 & $(31.0 \%)$ \\
\hline \multicolumn{3}{|l|}{ Main diagnosis } \\
\hline pulmonary disease & 15 & $(21.1 \%)$ \\
\hline neurologic disease & 18 & $(25.4 \%)$ \\
\hline trauma & 9 & $(12.7 \%)$ \\
\hline cardiac disease & 5 & $(7.0 \%)$ \\
\hline surgical procedure & 4 & $(5.6 \%)$ \\
\hline vascular disease & 3 & $(4.2 \%)$ \\
\hline not specified & 17 & $(23.9 \%)$ \\
\hline \multicolumn{3}{|l|}{ Type of intensive care unit } \\
\hline interdisciplinary & 13 & $(18.3 \%)$ \\
\hline surgical & 11 & $(15.5 \%)$ \\
\hline medical & 7 & $(9.9 \%)$ \\
\hline neurological & 6 & $(8.5 \%)$ \\
\hline cardiothoracic & 1 & $(1.4 \%)$ \\
\hline trauma & 3 & $(4.2 \%)$ \\
\hline not specified & 30 & $(42.3 \%)$ \\
\hline $\begin{array}{l}\text { Median duration of intubation before } \\
\text { tracheostomy (days) }\end{array}$ & 11 & (range $0-33$ \\
\hline
\end{tabular}

and/or hypoxemia. Chronic obstructive pulmonary disease (three cases) was stated as underlying condition putting patients at risk for this type of complication.

\section{Bronchospasm}

Three deaths (4.4\%) due to bronchospasm were reported $[33,45,53]$. Severe acute respiratory distress syndrome (ARDS) (two cases) and chronic obstructive pulmonary disease (one case) were stated as underlying conditions putting patients at risk for this type of complication.

\section{Cardiac arrest/arrhythmia}

Three intraprocedural deaths (4.4\%) due to cardiac arrest were reported [41,50,57]. Cardiac disease and surgery to the heart were recognized as underlying conditions putting patients at risk for this type of complication.

\section{Sepsis}

One death (1.5\%) was due to sepsis [21]. Sepsis was due to mediastinitis originating from the tracheostomy site. Previous sternotomy performed for the treatment of an aneurysm of the thoracic aorta was identified as a risk factor.

\section{Mortality rate}

The mean mortality rate calculated from retrospective studies, prospective observational studies and randomized trials included in this study and overlooking 8,324 PDT procedures was $2.18 \%$.

Departmental data could be obtained from 17 departments responsible for a total number of 24,307 PDT procedures and 42 fatalities. The incidence of death attributable to PDT calculated from these numbers was $0.17 \%$.

In our own department 1,873 patients underwent PDT between 1 January 2005 and 31 December 2012 and three procedure-related fatalities occurred resulting in an incidence of PDT-related lethal complications of $0.16 \%$.

\section{Discussion}

We analyzed 71 cases of death due to PDT. The incidence of death related to PDT calculated from departmental data provided by corresponding authors was $0.17 \%$, which is in line with the lethal complication rate 
Table 3 Causes and time of death after PDT

\begin{tabular}{|c|c|c|c|c|c|c|}
\hline \multirow{3}{*}{$\begin{array}{l}\text { Cause of death } \\
\text { Total number } \\
\end{array}$} & \multicolumn{2}{|c|}{ Total number } & \multicolumn{4}{|c|}{ Time of death } \\
\hline & & & \multicolumn{2}{|c|}{ Intra-procedural } & \multicolumn{2}{|c|}{ Post-procedural } \\
\hline & 71 & & 22 & $(31.0 \%)$ & 49 & $(69.0 \%)$ \\
\hline Hemorrhage & 27 & $(38.0 \%)$ & 3 & $(11.1 \%)$ & 24 & $(88.9 \%)$ \\
\hline - innominate artery & 11 & $(40.7 \%)$ & & & 11 & $(100.0 \%)$ \\
\hline - aortic arch & 2 & $(7.4 \%)$ & & & 2 & $(100.0 \%)$ \\
\hline - subclavian artery & 1 & $(3.7 \%)$ & 1 & $(100.0 \%)$ & & \\
\hline - thyroid artery & 1 & $(3.7 \%)$ & & & 1 & $(100.0 \%)$ \\
\hline - other artery & 1 & $(3.7 \%)$ & 1 & $(100.0 \%)$ & & \\
\hline - venous & 5 & $(18.5 \%)$ & 1 & $(20.0 \%)$ & 4 & $(80.0 \%)$ \\
\hline - diffuse/unknown & 6 & $(22.2 \%)$ & & & 6 & $(100.0 \%)$ \\
\hline Airway complications & 21 & $(29.6 \%)$ & 7 & $(33.3 \%)$ & 14 & $(66.7 \%)$ \\
\hline - dislocation of the tracheal cannula & 11 & $(52.4 \%)$ & 1 & $(9.1 \%)$ & 10 & $(90.9 \%)$ \\
\hline - lost airway during the procedure & 4 & $(19.0 \%)$ & 3 & $(75.0 \%)$ & 1 & $(25.0 \%)$ \\
\hline - paratracheal misplacement of the tracheal cannula & 3 & $(14.3 \%)$ & 3 & $(100.0 \%)$ & & \\
\hline - obstruction of tracheal cannula & 2 & $(9.5 \%)$ & & & 2 & $(100.0 \%)$ \\
\hline - hypoxemia during cannula replacement & 1 & $(4.8 \%)$ & & & 1 & $(100.0 \%)$ \\
\hline Tracheal perforation & 11 & $(15.5 \%)$ & 1 & $(9.1 \%)$ & 10 & $(90.9 \%)$ \\
\hline Pneumothorax & 4 & $(5.6 \%)$ & 4 & $(100.0 \%)$ & & \\
\hline Bronchospasm & 3 & $(4.2 \%)$ & 3 & $(100.0 \%)$ & & \\
\hline Cardiac arrest/arrhythmia & 3 & $(4.2 \%)$ & 3 & $(100.0 \%)$ & & \\
\hline Sepsis & 1 & $(1.4 \%)$ & & & 1 & $(100.0 \%)$ \\
\hline Unknown & 1 & $(1.4 \%)$ & 1 & (100.0\%) & & \\
\hline
\end{tabular}

in our own institution. The main reasons for the catastrophic events resulting in death were vascular injuries and airway complications. We found specific risk factors in $73.2 \%$ of patients, and $25.4 \%$ of patients had more than one risk factor. To the best of our knowledge this is the first systematic analysis of lethal complications due to PDT.

Gilbey et al. recently published a case series of fatal cases due to PDT and concluded that this event usually results from vascular injury [32]. However, their report included only seven cases, without providing further information about demographics, PDT technique, use of bronchoscopy or ultrasound.

Even after surgical tracheostomy, fatal complications can occur. In a survey of members of the American Academy of Otolaryngology, Head and Neck Surgery two-thirds of (mainly surgical) tracheostomy-related catastrophic events were reported to be mainly due to loss of airway or bleeding [8].

Tracheostomy-related hemorrhage was the most common cause of death in our study. Massive hemorrhage is a rare but devastating complication after any form of tracheostomy and usually originates from tracheoarterial fistula formation. The majority of cases occur within three days to six weeks of tracheostomy, and risk factors include pressure necrosis from high cuff pressure, mucosal trauma, malpositioned cannula tip, low tracheal incision, excessive neck movement, radiotherapy, or prolonged intubation [26]. We found such risk factors in $77.8 \%$ of these patients. In $29.6 \%$ of studied patients with fatal bleeding, performing the procedure without bronchoscopy was determined as a risk factor. In this group, placement of tracheostomy was too low in five patients, of which two had an aortic arch laceration. Coagulation dysfunction or platelet dysfunction were present in five patients. These were not deemed to be the primary cause of bleeding in two cases as these patients died from acute and sudden bleeding from specific blood vessels and without diffuse bleeding. Indeed, it has been shown previously, that even in severe thrombocytopenia, PDT can be safely performed after preprocedural correction [62].

A major risk factor seems to be a low tracheal incision, as was the case in five of twenty-seven patients with bleeding complications in our study. The site of puncture should ideally be selected between first and second or second and third tracheal rings [63]. In one study, the site of tracheal puncture was changed in $24 \%$ of patients as a result of prior ultrasound [64]. Furthermore, preprocedural ultrasound and clinical examination have been used to detect abnormal pretracheal vascular anatomy. Therefore, several authors recommend ultrasound to improve the safety of PDT [64-67]. 
The second most frequent cause of death was airway complications. The tracheal cannula was placed outside the tracheal lumen in three cases. Of note, in all of these cases bronchoscopic guidance was not used. Despite the lack of randomized controlled trials many authors think that the use of bronchoscopic guidance significantly increases the safety of PDT as it can guide correct placement of the introducer needle, the guidewire, and the cannula during the procedure $[68,69]$.

In a further 11 patients, the tracheal cannula accidentally dislocated postprocedurally. While the surgical approach allows easy reinsertion of the tracheal cannula, airway complications such as accidental decannulation or tube obstruction are well-described problems of the percutaneous technique [70]. Some researchers have proposed that fixing the tracheal cannula to the skin with sutures for the first postprocedural week may decrease cannula-related complications such as accidental decannulation and postoperative bleeding [71,72].

In two of the eleven deaths (18.2\%) due to posterior tracheal wall perforation, kinking of the guidewire was noticed after its removal during the procedure. Other researchers have postulated guidewire kinking as a possible mechanism for perforation of the posterior tracheal wall $[73,74]$. Thus, kinking of the guidewire must be avoided and its occurrence should raise suspicion of potential injury to the posterior tracheal wall prompting further investigation.

To avoid complications, PDT should only be considered in selected patients without contraindications. Contraindications to PDT include anatomic distortion of the neck, the presence of a difficult airway, severe ARDS, uncorrectable coagulopathy, and the presence of an unstable cervical spine [68]. However, most of these contraindications are relative and also dependent on the skill of the operator. Of the ten cases $(14.1 \%)$ in our study, where the performing team was deemed to be relatively inexperienced in the procedure, contraindications were also present in two patients (20.0\%).

Because of the growing numbers of patients requiring ventilatory support, the frequency of tracheostomy in the ICU has increased over the last decades as has the number of PDT-related publications (Additional file 1). In addition, it is conceivable that after the introduction and widespread acceptance of percutaneous techniques, enthusiasm about the ease of performing this procedure at the bedside may have resulted in relative overuse by intensivists.

A general limitation of this systematic review is the possibility of under- or over-estimating the true incidence of PDT-related death. Accurate risk assessment in clinical medicine is most difficult when an event is rare and available evidence is based on self-reported data [75]. Additionally, concerning the topic of this study, there is sometimes considerable difficulty in differentiating whether an adverse event is due to being critically ill with a tracheostomy or whether it is a complication of the PDT procedure itself. However, in all cases included in this study, the authors of the original publications judged death to be most likely related to the PDT procedure itself. Calculated from departmental data provided by the corresponding authors - where we are confident of both the completeness of reporting and the denominator - the mortality rate from PDT was $0.17 \%$. This is very much in line with the mortality rate of $0.16 \%$ reported in the largest study published to date [39] and the mortality rate of $0.16 \%$ in our own institution.

In our opinion, this first systemic analysis of the incidence and causes of PDT-related lethal complications adds important evidence to the literature and serves to remind clinicians about potentially life-threatening complications and to help them minimize risk factors by choosing suitable patients and safe procedural strategies.

\section{Conclusions}

In conclusion, PDTs, which are frequently performed in ICUs worldwide, are associated with an average mortality of one in every six hundred procedures. Major risk factors are present in a substantial proportion of these patients. To prevent severe complications, the results of this systematic review, several authors and professional guidelines suggest that the following measures may improve the safety of PDT: strict consideration of contraindications, bronchoscopic guidance during the entire procedure, performance by an experienced team, avoidance of a low tracheostomy puncture site and avoidance of guidewire kinking as well as the use of outer flange tracheal cannula sutures.

\section{Key messages}

- PDT-related death occurs in one out of six hundred procedures.

- Careful patient selection, bronchoscopic guidance, and securing the tracheal cannula with sutures are likely to reduce complication rates.

\section{Additional file}

Additional file 1: Number of publications reporting PDT-related fatalities and total number of publications on PDT procedures.

\section{Abbreviations}

ARDS: Acute respiratory distress syndrome; ICU: Intensive care unit; PDT: Percutaneous dilatational tracheostomy.

\section{Competing interests}

The authors declare that they have no competing interests. 


\section{Authors' contributions}

MS, MM and SK have made substantial contributions to conception and design of the study as well as to the acquisition, analysis and interpretation of data. SB and KP have made substantial contributions to analysis and interpretation of data. MS, MM and SK have drafted the submitted manuscript. SB and KP have revised it critically for important intellectual content. All authors read and approved the final manuscript.

\section{Author details}

'Department of Intensive Care Medicine, University Medical Center Hamburg-Eppendorf, Martinistr 52, 20246 Hamburg, Germany. ${ }^{2}$ Department of Forensic Medicine, University Medical Center Hamburg-Eppendorf, Hamburg, Germany.

Received: 8 May 2013 Accepted: 7 October 2013 Published: 29 October 2013

\section{References}

1. Cox CE, Carson SS, Holmes GM, Howard A, Carey TS: Increase in tracheostomy for prolonged mechanical ventilation in North Carolina, 1993-2002. Crit Care Med 2004, 32:2219-2226.

2. Simpson TP, Day CJ, Jewkes CF, Manara AR: The impact of percutaneous tracheostomy on intensive care unit practice and training. Anaesthesia 1999, 54:186-189.

3. Needham DM, Bronskill SE, Calinawan JR, Sibbald WJ, Pronovost PJ, Laupacis A: Projected incidence of mechanical ventilation in Ontario to 2026: Preparing for the aging baby boomers. Crit Care Med 2005, 33:574-579.

4. Zilberberg MD, de Wit M, Pirone JR, Shorr AF: Growth in adult prolonged acute mechanical ventilation: implications for healthcare delivery. Crit Care Med 2008, 36:1451-1455

5. Wang F, Wu Y, Bo L, Lou J, Zhu J, Chen F, Li J, Deng X: The timing of tracheotomy in critically ill patients undergoing mechanical ventilation: a systematic review and meta-analysis of randomized controlled trials. Chest 2011, 140:1456-1465.

6. Kluge S, Baumann HJ, Maier C, Klose H, Meyer A, Nierhaus A, Kreymann G: Tracheostomy in the intensive care unit: a nationwide survey. Anesth Analg 2008, 107:1639-1643.

7. Freeman BD, Morris PE: Tracheostomy practice in adults with acute respiratory failure. Crit Care Med 2012, 40:2890-2896.

8. Das P, Zhu H, Shah RK, Roberson DW, Berry J, Skinner ML: Tracheotomyrelated catastrophic events: results of a national survey. Laryngoscope 2012, 122:30-37.

9. Liberati A, Altman DG, Tetzlaff J, Mulrow C, Gøtzsche PC, loannidis JPA Clarke M, Devereaux PJ, Kleijnen J, Moher D: The PRISMA statement for reporting systematic reviews and meta-analyses of studies that evaluate health care interventions: explanation and elaboration. PLoS Med 2009, 6:e1000100.

10. Ciaglia P, Firsching R, Syniec C: Elective percutaneous dilatational tracheostomy. A new simple bedside procedure: preliminary report. Chest 1985, 87:715-719.

11. Braune S, Kluge S: [Die perkutane Dilatationstracheotomie]. Dtsch Med Wochenschr 2011, 136:1265-1269.

12. Dempsey GA, Grant CA, Jones TM: Percutaneous tracheostomy: a 6 year prospective evaluation of the single tapered dilator technique. $\mathrm{Br} J$ Anaesth 2010, 105:782-788

13. Hill BB, Zweng TN, Maley RH, Charash WE, Toursarkissian B, Kearney PA: Percutaneous dilational tracheostomy: report of 356 cases. J Trauma $1996,41: 238-243$

14. Toursarkissian B, Zweng TN, Kearney PA, Pofahl WE, Johnson SB, Barker DE: Percutaneous dilational tracheostomy: report of 141 cases. Ann Thorac Surg 1994, 57:862-867.

15. Cobean R: Personal communication

16. Byhahn C: Personal communication.

17. Hutchinson RC, Mitchell RD: Life-threatening complications from percutaneous dilational tracheostomy. Crit Care Med 1991, 19:118-120.

18. Cokis C, Towler S: Tracheo-innominate fistula after initial percutaneous tracheostomy. Anaesth Intensive Care 2000, 28:566-569.

19. Hürter H, Post-Stanke A: [Tödliche Gefäßarrosion nach Dilatationstracheotomie]. Anasthesiol Intensivmed Notfallmed Schmerzther 2000, 35:658-660.
20. Drage SM, Pac Soo C, Dexter T: Delayed presentation of tracheooesophageal fistula following percutaneous dilatational tracheostomy. Anaesthesia 2002, 57:932-933.

21. Maeda K, Ninomiya M, Moyairi T, Morota T, Kitamura R, Takamoto S: Mediastinitis after percutaneous dilatational tracheostomy. Thorac Cardiovasc Surg 2002, 50:123-124.

22. Soubirou JL, Puidupin A, Augeul G, Leclerc T, Combourieu E, Patrigeon RG, Escarment J: [Complication sévère après une trachéotomie translaryngée]. Ann Fr Anesth Reanim 2002, 21:728-730.

23. Ryan DW, Kilner AJ: Another death after percutaneous dilational tracheostomy. Br J Anaesth 2003, 91:925-926.

24. Shlugman D, Satya-Krishna R, Loh L: Acute fatal haemorrhage during percutaneous dilatational tracheostomy. $\mathrm{Br}$ J Anaesth 2003, 90:517-520.

25. McCormick B, Manara AR: Mortality from percutaneous dilatational tracheostomy. A report of three cases. Anaesthesia 2005, 60:490-495.

26. Grant CA, Dempsey G, Harrison J, Jones T: Tracheo-innominate artery fistula after percutaneous tracheostomy: three case reports and a clinical review. Br J Anaesth 2006, 96:127-131.

27. Rosolski T: [Spannungspneumothorax Nach Punktionstracheotomie]. J Anaesth Intensivbehandlung 2006, 3:36.

28. Ayoub OM, Griffiths MV: Aortic arch laceration: A lethal complication after percutaneous tracheostomy. Laryngoscope 2007, 117:176-178.

29. Zehlicke T, Dommerich S, Rummel J: [Letale Blutung aus dem Truncus brachiocephalicus - Spätkomplikation nach Fehleinschätzung eines Dilatationstracheostomas bei rudimentärer Halsrippe]. Laryngorhinootologie 2007, 86:655-659.

30. Wang P-K, Yen P-S, Shyr M-H, Chen T-Y, Chen A, Liu H-T: Endovascular repair of tracheo-innominate artery fistula. Acta Anaesthesiol Taiwan 2009, 47:36-39.

31. Hoiting O, van den Brule J, van Zwam PH: Late fatal bleeding after percutaneous dilatational tracheostomy. Neth J Crit Care 2010, 14:335-337.

32. Gilbey P: Fatal complications of percutaneous dilatational tracheostomy. Am J Otolaryngol 2012, 32:770-773.

33. Ivatury R, Siegel JH, Stahl WM, Simon R, Scorpio R, Gens DR: Percutaneous tracheostomy after trauma and critical illness. J Trauma 1992, 32:133-140.

34. Cobean R, Beals M, Moss C: Percutaneous dilatational tracheostomy: a safe, cost-effective bedside procedure. Arch Surg 1996, 131:265-271.

35. van Heurn LW, van Geffen GJ, Brink PR: Clinical experience with percutaneous dilatational tracheostomy: report of 150 cases. Eur J Surg 1996, 162:531-535.

36. Thompson EC, Fernandez LG, Norwood S, Wilkins H, Vallina VL: Percutaneous dilatational tracheostomy in a community hospital setting. South Med J 2001, 94:208-211.

37. Pandit RA, Jacques TC: Audit of over 500 percutaneous dilational tracheostomies. Crit Care Resusc 2006, 8:146-150.

38. Klein M, Agassi R, Shapira A-R, Kaplan DM, Koiffman L, Weksler N: Can intensive care physicians safely perform percutaneous dilational tracheostomy? An analysis of 207 cases. Isr Med Assoc J 2007, 9:717-719

39. Dennis BM, Eckert MJ, Gunter OL, Morris JA, May AK: Safety of bedside percutaneous tracheostomy in the critically ill: evaluation of more than 3,000 procedures. J Am Coll Surg 2013, 216:858-867.

40. Toye FJ, Weinstein JD: Clinical experience with percutaneous tracheostomy and cricothyroidotomy in 100 patients. J Trauma 1986, 26:1034-1040.

41. Marelli D, Paul A, Manolidis S, Walsh G, Odim JN, Burdon TA, Shennib H, Vestweber KH, Fleiszer DM, Mulder DS: Endoscopic guided percutaneous tracheostomy: early results of a consecutive trial. J Trauma 1990, 30:433-435.

42. Wang MB, Berke GS, Ward PH, Calcaterra TC, Watts D: Early experience with percutaneous tracheotomy. Laryngoscope 1992, 102:157-162.

43. Friedman Y, Mayer AD: Bedside percutaneous tracheostomy in critically ill patients. Chest 1993, 104:532-535.

44. Cole IE: Elective percutaneous (Rapitrac) tracheotomy: results of a prospective trial. Laryngoscope 1994, 104:1271-1275.

45. Barba C, Angood P, Kauder D, Latenser B: Bronchoscopic guidance makes percutaneous tracheostomy a safe, cost-effective, and easy-to-teach procedure. Surgery 1995, 118:879-883.

46. Muhl E, Franke C, BRUCH HP: [Verbesserte Technik der Dilatationstracheostomie und erste Ergebnisse]. Anasthesiol Intensivmed Notfallmed Schmerzther 1995, 30:497-500.

47. Joosten U, Sturbeck K, Hohlbach G: [Die Punktionstracheotomie beim langzeitbeatmeten Intensivpatienten]. Langenbecks Arch Chir Suppl Kongressbd 1996, 113:356-359. 
48. Marx WH, Ciaglia P, Graniero KD: Some important details in the technique of percutaneous dilatational tracheostomy via the modified Seldinger technique. Chest 1996, 110:762-766.

49. Berrouschot J, Oeken J, Schneider D: Perioperative complications of percutaneous dilational tracheostomy. Laryngoscope 1997, 107:1538-1544.

50. Walz MK, Peitgen K, Thürauf N, Trost HA, Wolfhard U, Sander A, Ahmadi C, Eigler FW: Percutaneous dilatational tracheostomy-early results and long-term outcome of 326 critically ill patients. Intensive Care Med 1998, 24:685-690

51. Suh RH, Margulies DR, Hopp ML, Ault M, Shabot MM: Percutaneous dilatational tracheostomy: still a surgical procedure. Am Surg 1999, 65:982-986.

52. Escarment J, Suppini A, Sallaberry M, Kaiser E, Cantais E, Palmier B, Quinot JF: Percutaneous tracheostomy by forceps dilation: report of 162 cases. Anaesthesia 2000, 55:125-130.

53. Kearney PA, Griffen MM, Ochoa JB, Boulanger BR, Tseui BJ, Mentzer RM: A single-center 8-year experience with percutaneous dilational tracheostomy. Ann Surg 2000, 231:701-709.

54. Lim JW, Friedman M, Tanyeri H, Lazar A, Caldarelli DD: Experience with percutaneous dilational tracheostomy. Ann Otol Rhinol Laryngol 2000, 109:791-796.

55. Norwood S, Vallina VL, Short K, Saigusa M, Fernandez LG, McLarty JW: Incidence of tracheal stenosis and other late complications after percutaneous tracheostomy. Ann Surg 2000, 232:233-241.

56. Tan C, Lee H: Percutaneous dilational tracheostomy - a 3 year experience in a general hospital in Malaysia. Med J Malaysia 2004, 59:591-597.

57. Byhahn C, Lischke V, Meininger D, Halbig S, Westphal K: Peri-operative complications during percutaneous tracheostomy in obese patients. Anaesthesia 2005, 60:12-15.

58. Chiu C-T, Chung Y-H, Lu H-I, Lin M-C: Weaning of long-term mechanicallyventilated patients following video bronchoscopy-guided percutaneous dilatational tracheostomy. Chang Gung Med J 2005, 28:829-836.

59. Páez M, Buisán F, Almaraz A, Martínez-Martínez A, Muñoz F: Percutaneous tracheotomy with the Ciaglia Blue Rhino technique: a critical analysis after 1 year. Rev Esp Anestesiol Reanim 2005, 52:466-473.

60. Porter JM, Ivatury RR: Preferred route of tracheostomy-percutaneous versus open at the bedside: a randomized, prospective study in the surgical intensive care unit. Am Surg 1999, 65:142-146.

61. Massick DD, Yao S, Powell DM, Griesen D, Hobgood T, Allen JN, Schuller DE: Bedside tracheostomy in the intensive care unit: a prospective randomized trial comparing open surgical tracheostomy with endoscopically guided percutaneous dilational tracheotomy. Laryngoscope 2001, 111:494-500.

62. Kluge S, Meyer A, Kühnelt P, Baumann HJ, Kreymann G: Percutaneous tracheostomy is safe in patients with severe thrombocytopenia. Chest 2004, 126:547-551.

63. Australian and New Zealand Intensive Care Society: Percutaneous Dilatational Tracheostomy Consensus Statement. 2010.

64. Kollig E, Heydenreich U, Roetman B, Hopf F, Muhr G: Ultrasound and bronchoscopic controlled percutaneous tracheostomy on trauma ICU. Injury 2000, 31:663-668.

65. Rajajee V, Fletcher JJ, Rochlen LR, Jacobs TL: Real-time ultrasound-guided percutaneous dilatational tracheostomy: a feasibility study. Crit Care 2011 15:R67.

66. Otchwemah R, Defosse J, Wappler F, Sakka SG: Percutaneous dilatation tracheostomy in the critically ill: use of ultrasound to detect an aberrant course of the brachiocephalic trunk. J Cardiothorac Vasc Anesth 2012, 26:e72-e73.

67. Rudas M, Seppelt I: Safety and efficacy of ultrasonography before and during percutaneous dilatational tracheostomy in adult patients: a systematic review. Crit Care Resusc 2012, 14:297-301.

68. Braune S, Kluge S: Update Tracheotomie. Med Klin Intensivmed Notfmed 2012, 107:543-547.

69. De Leyn P, Bedert L, Delcroix M, Depuydt P, Lauwers G, Sokolov Y, Van Meerhaeghe A, Van Schil P, Belgian Association of Pneumology and Belgian Association of Cardiothoracic Surgery: Tracheotomy: clinical review and guidelines. Eur J Cardiothorac Surg 2007:412-421.

70. Higgins KM, Punthakee $X$ : Meta-analysis comparison of open versus percutaneous tracheostomy. Laryngoscope 2007, 117:447-454.

71. Halum SL, Ting JY, Plowman EK, Belafsky PC, Harbarger CF, Postma GN, Pitman MJ, LaMonica D, Moscatello A, Khosla S, Cauley CE, Maronian NC,
Melki S, Wick C, Sinacori JT, White Z, Younes A, Ekbom DC, Sardesai MG, Merati AL: A multi-institutional analysis of tracheotomy complications. Laryngoscope 2012, 122:38-45.

72. Beiderlinden M, Karl Walz M, Sander A, Groeben H, Peters J: Complications of bronchoscopically guided percutaneous dilational tracheostomy: beyond the learning curve. Intensive Care Med 2002, 28:59-62.

73. Byhahn C, Wilke HJ, Halbig S, Lischke V, Westphal K: Percutaneous tracheostomy: ciaglia blue rhino versus the basic ciaglia technique of percutaneous dilational tracheostomy. Anesth Analg 2000, 91:882-886.

74. Thant M, Samuel T: Posterior tracheal wall tear with PercuTwist. Anaesthesia 2002, 57:507-508.

75. Eibling DE, Roberson DW: Managing tracheotomy risk: time to look beyond hospital discharge. Laryngoscope 2012, 122:23-24.

\section{doi: $10.1186 /$ cc13085}

Cite this article as: Simon et al:: Death after percutaneous dilatational tracheostomy: a systematic review and analysis of risk factors. Critical Care 2013 17:R258

\section{Submit your next manuscript to BioMed Central and take full advantage of:}

- Convenient online submission

- Thorough peer review

- No space constraints or color figure charges

- Immediate publication on acceptance

- Inclusion in PubMed, CAS, Scopus and Google Scholar

- Research which is freely available for redistribution 